\title{
Cellular Metabolomics Reveal the Mechanism Underlying the Anti-Atherosclerotic Effects of Aspirin Eugenol Ester on Vascular Endothelial Dysfunction
}

\author{
Mei-Zhou Huang ${ }^{+}{ }^{\circ}$, Xiao-Rong Lu ${ }^{\dagger}$, Ya-Jun Yang, Xi-Wang Liu, Zhe Qin and Jian-Yong Li * \\ Key Lab of New Animal Drug Project of Gansu Province, Key Lab of Veterinary Pharmaceutical Development of \\ Ministry of Agriculture, Lanzhou Institute of Husbandry and Pharmaceutical Sciences of CAAS, \\ Lanzhou 730050, China \\ * Correspondence: lijy1971@163.com or lijianyong@caas.cn; Tel./Fax: +86-931-2115290 \\ + These authors have contributed equally to this work.
}

Received: 18 June 2019; Accepted: 26 June 2019; Published: 28 June 2019

\begin{abstract}
Aspirin eugenol ester (AEE) possesses anti-thrombotic, anti-atherosclerotic and anti-oxidative effects. The study aims to clarify the mechanism underlying the anti-atherosclerotic effects of AEE on vascular endothelial dysfunction. Both the high-fat diet (HFD)-induced atherosclerotic rat model and the $\mathrm{H}_{2} \mathrm{O}_{2}$-induced human umbilical vein endothelial cells (HUVECs) model were used to investigate the effects of AEE on vascular endothelial dysfunction. UPLC/QTOF-MS coupled with a multivariate data analysis method were used to profile the variations in the metabolites of HUVECs in response to different treatments. Pretreatment of HUVECs with AEE significantly ameliorated $\mathrm{H}_{2} \mathrm{O}_{2}$-induced apoptosis, the overexpression of E-selectin and VCAM-1, and the adhesion of THP- 1 cells. Putative endogenous biomarkers associated with the inhibition of endothelial dysfunction were identified in HUVECs pretreated with AEE in the absence or presence of $\mathrm{H}_{2} \mathrm{O}_{2}$, and these biomarkers were involved in important metabolic pathways, including amino acid metabolism, carbohydrate metabolism, and glutathione metabolism. Moreover, in vivo, AEE also significantly reduced vascular endothelial dysfunction and decreased the overexpression of VCAM-1 and E-selectin. Based on our findings, the mechanism underlying the anti-atherosclerotic effects of AEE might be related to a reduction in vascular endothelial dysfunction mediated by ameliorating alterations in metabolism, inhibiting oxidative stress, and decreasing the expression of adhesion molecules.
\end{abstract}

Keywords: aspirin eugenol ester; vascular endothelium; cell metabolomics

\section{Introduction}

The endothelium has been regarded as a pivotal regulator of vascular homeostasis [1,2] Dysfunctional, activated endothelium induced by various stimuli may increase leukocyte adhesion and the production of cytokines and growth factors, which would promote the development of atherosclerosis, a thrombus and other cardiovascular diseases [3-8]. An appreciation of the key role of the endothelium in the cardiovascular disease process has led to the development of new drugs to regulate its function $[9,10]$.

AEE is synthesized by combining aspirin with eugenol based on the prodrug principal [11]. AEE possesses various pharmacological activities, including anti-thrombus, anti-atherosclerotic, and anti-oxidative properties [12-16]. The mechanism by which AEE regulates cardiovascular diseases remains unknown, although many in-vivo studies of AEE have been well documented by our 
group $[15,17,18]$. In-vitro investigations of AEE coupled with the application of new technical methods will be beneficial for clarifying the mechanism of action of AEE.

Metabolism, a ubiquitous biological process, reflects the state of the cells, tissue, organs and whole body in real time. Since metabolomics facilitates the high-throughput, global, and comprehensive characterization of small molecule metabolites in a biological system and their changes, it has been adopted to diagnose diseases, develop drugs and evaluate pharmacodynamics [19-23]. Recently, cellular metabolomics has been used to systematically investigate the small-molecule metabolites in specific cells $[24,25]$. Cellular metabolomics is also an ideal technical method to probe the effects of AEE on vascular endothelial cell dysfunction. In the present study, the effects of AEE on vascular endothelial cell dysfunction were investigated in vitro, and differences in the cellular metabolite levels between untreated human umbilical vein endothelial cells (HUVECs) and cells with $\mathrm{H}_{2} \mathrm{O}_{2}$ and/or AEE were evaluated to further understand the mechanism underlying the anti-atherosclerotic effects of AEE on vascular endothelial dysfunction. Moreover, the anti-atherosclerotic mechanism of AEE was confirmed in a rat model of HFD-induced atherosclerosis.

\section{Results}

\subsection{AEE Reduced the $\mathrm{H}_{2} \mathrm{O}_{2}$-Induced Apoptosis of HUVECS}

In order to detect the effects of AEE on $\mathrm{H}_{2} \mathrm{O}_{2}$-induced HUVECs, the $\mathrm{H}_{2} \mathrm{O}_{2}$-induced oxidative injury model of HUVECs was established. After treating HUVECs with $200 \mu \mathrm{M} \mathrm{H}_{2} \mathrm{O}_{2}$ for $22 \mathrm{~h}$, the percentage of early apoptotic cells was approximately $60 \%$. Pre-incubation of HUVECs with different concentrations of AEE $(0.5,1$, or $2 \mu \mathrm{M})$ for $24 \mathrm{~h}$ markedly decreased the percentage of early apoptotic HUVECs. Moreover, the pretreatment with $1 \mu \mathrm{M}$ AEE exerted the best effect (Figure 1A). The results suggested that AEE could effectively prevent $\mathrm{H}_{2} \mathrm{O}_{2}$-induced oxidative injury of HUVECs.

A

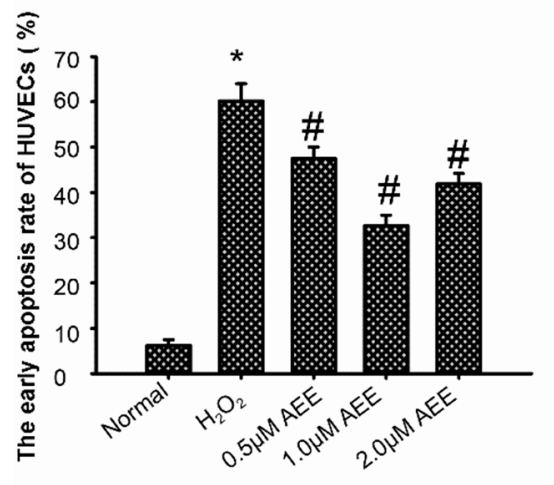

B

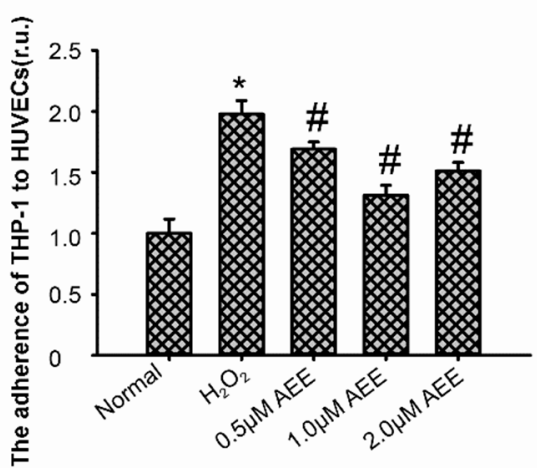

Figure 1. AEE reduced the apoptosis of HUVECs and decreased the $\mathrm{H}_{2} \mathrm{O}_{2}$-induced adherence of THP1 cells to HUVECs. (A) AEE reduced the apoptosis of HUVECs induced by $\mathrm{H}_{2} \mathrm{O}_{2}$. Values are presented as the means $\pm \mathrm{SD}$ where applicable $(n=6) .{ }^{*} p<0.05$ compared with the normal group; ${ }^{\#} p<0.05$ compared with the $\mathrm{H}_{2} \mathrm{O}_{2}$ group. (B) AEE decreased the $\mathrm{H}_{2} \mathrm{O}_{2}$-induced adherence of THP1 cells to HUVECs. Values are presented as the means \pm SD where applicable $(n=6)$. All data were normalized to the corresponding control and reported in relative units (r.u.).

\subsection{AEE Ameliorated Alterations in the Biochemical Profile}

To confirm whether the effects of AEE on vascular endothelial in vivo and in vitro are similar, the HFD-induced rat model of atherosclerosis was used to investigate anti-vascular endothelial dysfunction effects of AEE. The physiological biochemical parameters and AGE level of HFD-fed rats were significantly disturbed, as shown in Table 1 . The levels of LDL, TCH, and AGEs were markedly increased $(p<0.05)$, and the level of HDL was significantly decreased $(p<0.05)$ compared with the 
normal group. Meanwhile, the changes in the biochemical profile and AGE levels were significantly ameliorated in rats pretreated with AEE $(54 \mathrm{mg} / \mathrm{kg}$ body weight).

Table 1. The effects of AEE on serum biochemical indices and AGE levels.

\begin{tabular}{cccc}
\hline Variables & Normal Group & HFD Group & AEE Group \\
\hline HDL $(\mathrm{mmol} / \mathrm{L})$ & $0.96 \pm 0.10$ & $0.67 \pm 0.06^{*}$ & $0.79 \pm 0.02^{\#}$ \\
LDL $(\mathrm{mmol} / \mathrm{L})$ & $0.53 \pm 0.06$ & $0.80 \pm 0.19^{*}$ & $0.68 \pm 0.04^{\#}$ \\
TCH $(\mathrm{mmol} / \mathrm{L})$ & $1.24 \pm 0.10$ & $2.41 \pm 0.48^{*}$ & $1.58 \pm 0.34^{\#}$ \\
AGE $(\mathrm{ng} / \mathrm{mL})$ & $390.38 \pm 18.13$ & $786.64 \pm 49.20^{*}$ & $497.04 \pm 34.70^{\#}$ \\
\hline
\end{tabular}

HDL: high density lipoprotein; LDL: low density lipoprotein; TCH: total cholesterol; HFD: high-fat diet; AGE: advanced glycosylation end product. Values are presented as the means \pm SD where applicable $(n=8) .{ }^{*} p<0.05$ compared with the normal group; ${ }^{\#} p<0.05$ compared with the HFD group.

\subsection{AEE Suppressed the Oxidative Injury-Induced Imbalance in Vascular Adhesion}

The imbalance in vascular adhesion is a vital characteristic of vascular endothelial dysfunction. After treating HUVECs with $200 \mu \mathrm{M} \mathrm{H}_{2} \mathrm{O}_{2}$ for $22 \mathrm{~h}$, the adherence of THP- 1 cells to HUVECs was significantly increased in vitro. The pre-incubation with AEE $(0.5,1.0$, or $2.0 \mu \mathrm{M})$ significantly attenuated the adherence of THP-1 cells to HUVECs (Figure 1B). The expression of VCAM-1, ICAM-1, and E-selectin on HUVECs among the different treatment groups was detected using flow cytometry. As shown in Figure 2, the treatment of HUVECs with $200 \mu \mathrm{M} \mathrm{H}_{2} \mathrm{O}_{2}$ for $22 \mathrm{~h}$ significantly increased VCAM-1 and E-selectin expression. However, in the cells pretreated with AEE (0.5, 1.0, or $2.0 \mu \mathrm{M})$, the stimulatory effect of $\mathrm{H}_{2} \mathrm{O}_{2}$ on malondialdehyde (MDA) levels was significantly reduced. ICAM-1 expression was not different among the different treatment groups, and VCAM-1 expression was also not different between the AEE pretreatment group and $\mathrm{H}_{2} \mathrm{O}_{2}$-induced group. These findings suggested that AEE could effectively suppress the oxidative injury-induced imbalance in vascular adhesion.
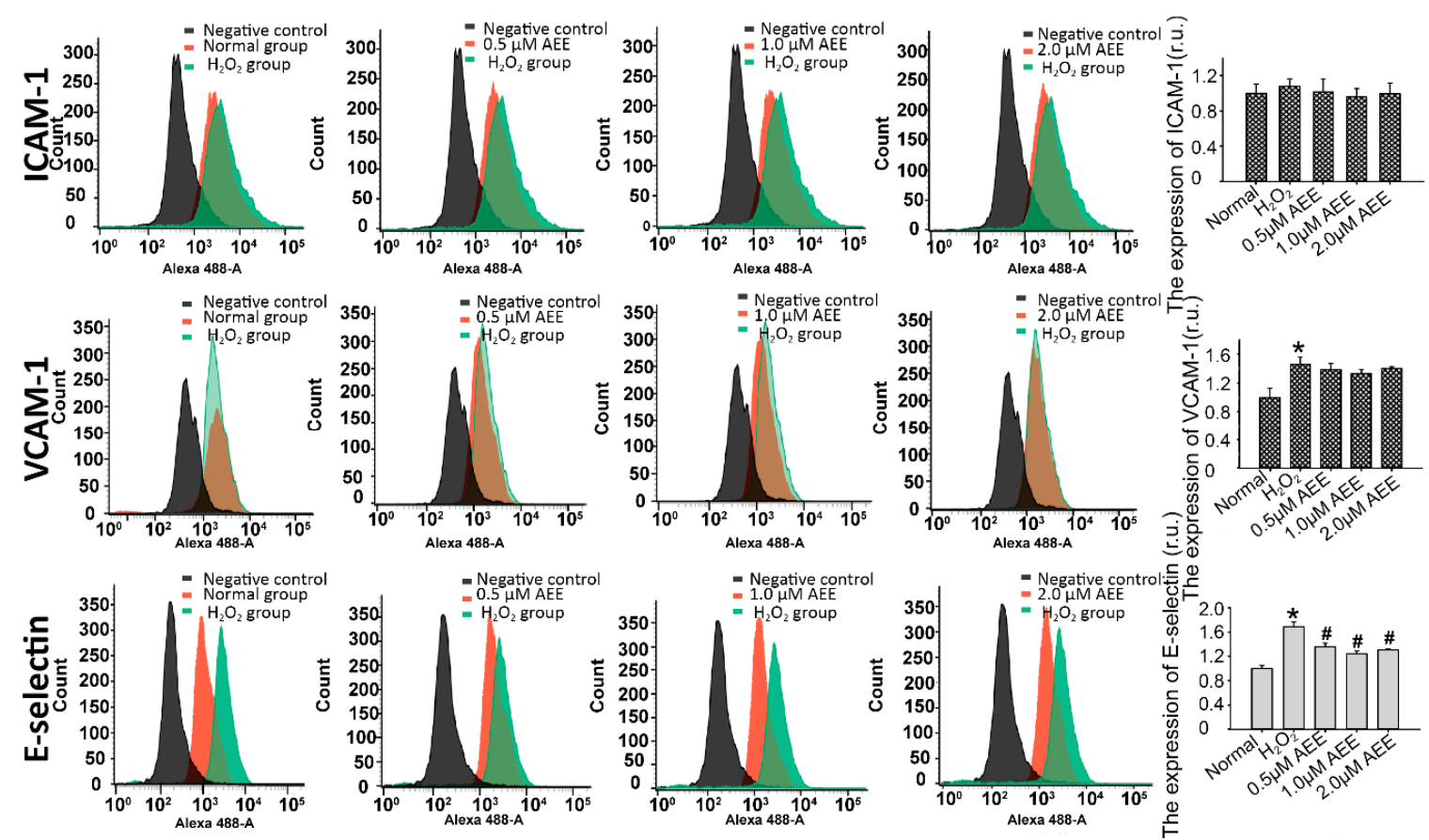

Figure 2. AEE decreased $\mathrm{H}_{2} \mathrm{O}_{2}$-induced E-selection expression in HUVECs. Values are presented as the means \pm SD where applicable $(n=8)$. ${ }^{*} p<0.05$ compared with the normal group; ${ }^{\#} p<0.05$ compared with the $\mathrm{H}_{2} \mathrm{O}_{2}$ group. All data were normalized to the corresponding control and in relative units (r.u.).

As shown in Figure 3, rats fed the HFD for 12 weeks exhibited a significant increase in VCAM-1 and E-selectin expression in the aorta in vivo compared with the normal group, while ICAM-1 expression 
in the aorta was not different between the HFD group and normal group. In rats pretreated with AEE ( $54 \mathrm{mg} / \mathrm{kg}$ body weight), the HFD-induced overexpression of VCAM- 1 and E-selectin was significantly reduced. Moreover, the serum levels of sVCAM-1 and sE-selectin were significantly increased in HFD-fed rats. In the presence of AEE, the levels of sVCAM- 1 and sE-selectin were significantly reduced compared with the HFD-fed groups. ICAM-1 levels were not significantly different among the different treatment groups. The results in vivo also proposed that AEE could effectively attenuate imbalance in vascular adhesion.

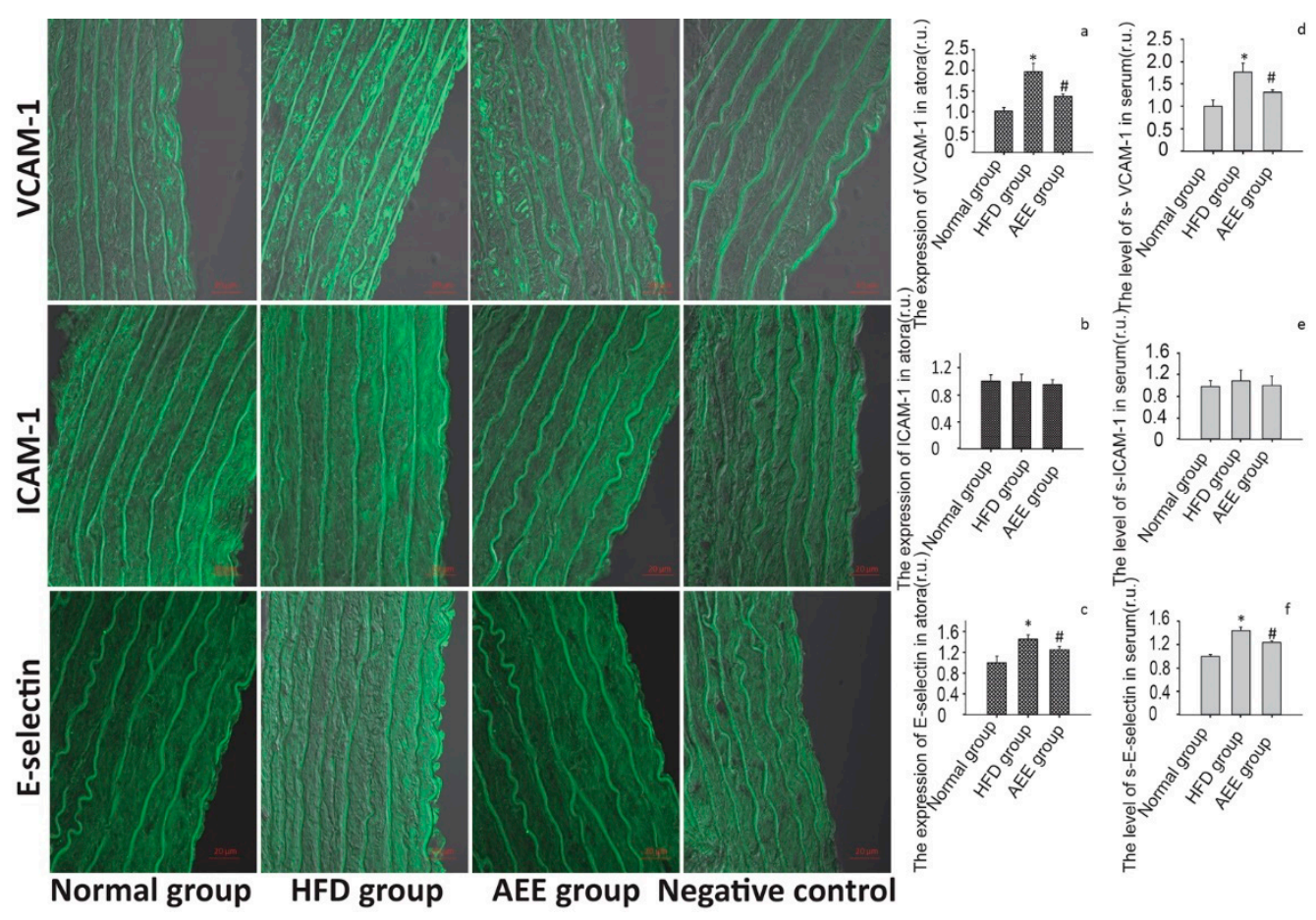

Figure 3. AEE reduced the expression of adhesion molecules in rats fed the HFD. (a-c): AEE reduced VCAM-1 and E-selectin expression in the aorta. Values are presented as the means \pm SD where applicable $(n=8)$. ${ }^{*} p<0.05$ compared with the normal group; ${ }^{*} p<0.05$ compared with the HFD group. All data were normalized to the corresponding control and reported in relative units (r.u.). (d-f): AEE decreased the serum sVCAM-1 and sE-selectin levels. Values are presented as the means \pm SD where applicable $(n=8)$. ${ }^{*} p<0.05$ compared with the normal group; ${ }^{\#} p<0.05$ compared with the HFD group. All data were normalized to the corresponding control and reported in relative units (r.u.).

\subsection{Metabolomics Analysis of Cells and Cell Culture Supernatants}

\subsubsection{Metabolomics Analysis of Cell Culture Supernatants}

The disorder of cell metabolism is an important incentive of imbalance in vascular adhesion. Therefore, the metabolomics of cells and cell culture supernatants was detected among different treatment groups using UPLC-Q-TOF/MS to determine the effect of AEE on the cellular metabolite levels. Representative total ion chromatograms (TICs) of the cells and cell culture supernatants showed good separation and strong sensitivity of the established method (Supplementary materials). Moreover, the number of metabolites is presented in the Supplementary materials. A principal component analysis (PCA) was performed to visualize grouping trends and outliers in the MS data of cell culture supernatants collected in positive and negative mode, respectively. As indicated by the score plots of the first two principal components ( $\mathrm{t} 1 / \mathrm{t} 2)$ shown in Figure $4 \mathrm{a}, \mathrm{b}$, the metabolic profiles of cell culture supernatants from the normal group and AEE group in the absence of $\mathrm{H}_{2} \mathrm{O}_{2}$ were clearly separated in positive and negative modes. The metabolic profiles of cell culture supernatants from the normal group, $\mathrm{H}_{2} \mathrm{O}_{2}$ group and $\mathrm{AEE}$ group were clearly separated in positive and negative modes 
(Figure $5 \mathrm{a}, \mathrm{b}$ ). The values for the model parameter R2X, which represent the explanatory ability of the model, were 0.627 and 0.625 in positive and negative modes, respectively, indicating that the data were highly elucidated by the two PCA models.
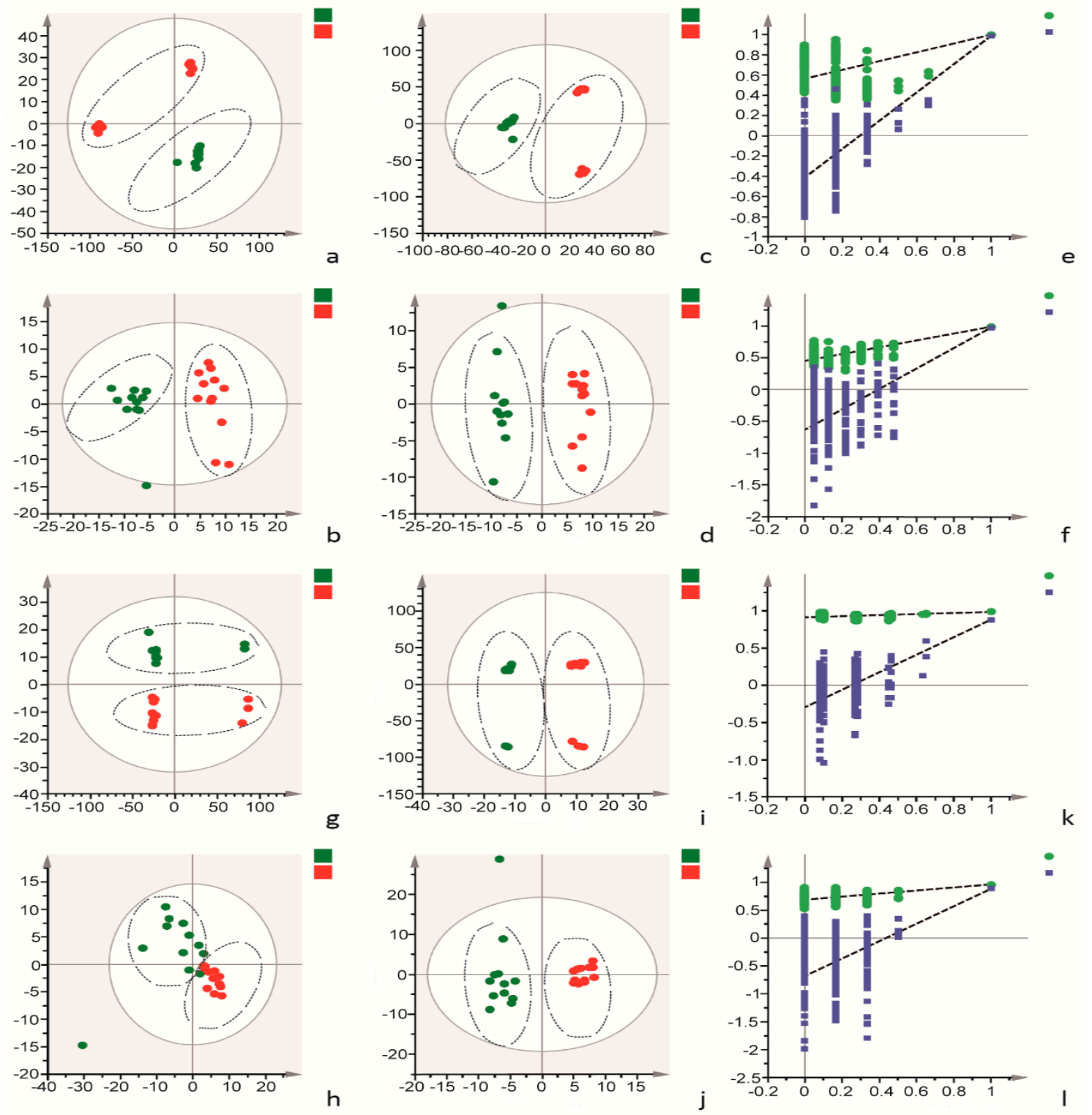

Figure 4. Multivariate analyses data from the UPLC-Q-TOF/MS analysis of cells and cell culture supernatants in the absence of $\mathrm{H}_{2} \mathrm{O}_{2}$. (a,b): PCA score plots based on cell culture supernatant metabolic profiles of the normal and AEE groups in positive and negative modes, ESI+: $\mathrm{R}^{2}=0.773$, ESI-: $R^{2}=0.602$. $(\mathbf{c}, \mathbf{d})$ : OPLS-DA score plots of normal and AEE groups in positive and negative modes, ESI+: $R^{2} X=0.773, R^{2} Y=0.993, Q^{2}=0.982 ; E S I-: R^{2} X=0.442, R^{2} Y=0.985, Q^{2}=0.971$. $(\mathbf{e}, \mathbf{f})$ : Permutation test of the OPLS-DA model, ESI+: the intercepts of $\mathrm{R}^{2}=0.512$ and $\mathrm{Q}^{2}=-0.424, \mathrm{ESI}-$ : the intercepts of $\mathrm{R}^{2}=0.469$ and $\mathrm{Q}^{2}=-0.615$. $(\mathrm{g}, \mathbf{h})$ : PCA score plots based on cellular metabolic profiles of the normal and AEE groups in positive and negative modes, ESI+: $R^{2}=0.778$, ESI-: $R^{2}=0.643$. $(\mathbf{i}, \mathbf{j})$ : OPLS-DA score plots of the normal and AEE groups in positive and negative modes, ESI+: $R^{2} X=0.795, R^{2} Y=0.99, Q^{2}=0.886 ; E S I-: R^{2} X=0.542, R^{2} Y=0.965, Q^{2}=0.885$. (k,l): Permutation test of the OPLS-DA model, ESI+: the intercepts of $\mathrm{R}^{2}=0.923$ and $\mathrm{Q}^{2}=-0.225$, ESI-: the intercepts of $\mathrm{R}^{2}=0.696$ and $\mathrm{Q}^{2}=-0.72$. Z: normal group; $\mathrm{B}$ : AEE group. 

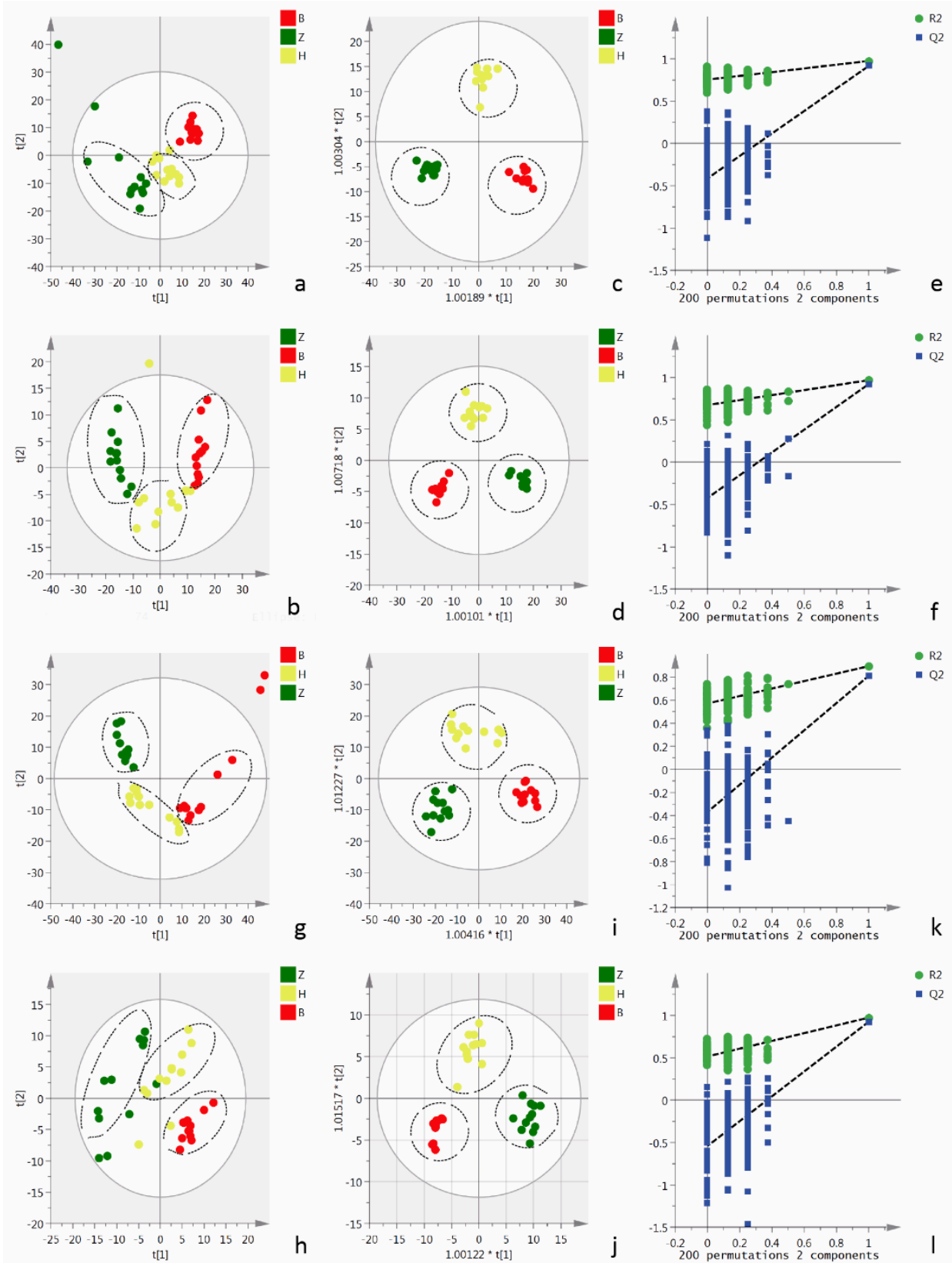

Figure 5. Multivariate analyses of data from the UPLC-Q-TOF/MS analysis of cell and cell culture supernatants stimulated with $\mathrm{H}_{2} \mathrm{O}_{2}$. (a,b): PCA score plots based on cell culture supernatant metabolic profiles of the normal, $\mathrm{H}_{2} \mathrm{O}_{2}$ and AEE groups in positive and negative modes, ESI+: $\mathrm{R}^{2}=0.527$, ESI-: $\mathrm{R}^{2}=0.593$. $(\mathbf{c}, \mathrm{d})$ : OPLS-DA score plots of the normal, $\mathrm{H}_{2} \mathrm{O}_{2}$ and AEE groups in positive and negative modes, ESI+: $R^{2} X=0.392, R^{2} Y=0.975, Q^{2}=0.862$; ESI-: $R^{2} X=0.511, R^{2} Y=0.966, Q^{2}=0.848$. $(\mathbf{e}, \mathbf{f})$ : Permutation test of the OPLS-DA model, ESI+: the intercepts of $\mathrm{R}^{2}=0.751$ and $\mathrm{Q}^{2}=-0.427$, ESI-: the intercepts of $\mathrm{R}^{2}=0.675$ and $\mathrm{Q}^{2}=-0.422$. $(\mathrm{g}, \mathrm{h})$ : PCA score plots based on the cellular metabolic profiles of the normal, $\mathrm{H}_{2} \mathrm{O}_{2}$ and AEE groups in positive and negative modes, ESI+: $\mathrm{R}^{2}=0.56$, ESI-: $\mathrm{R}^{2}=0.668$. (i,j): OPLS-DA score plots of normal and AEE groups in positive and negative modes, ESI+: $R^{2} X=0.4, R^{2} Y=0.911, Q^{2}=0.836$; ESI-: $R^{2} X=0.531, R^{2} Y=0.924, Q^{2}=0.814$. (k,l): Permutation test of the OPLS-DA model, ESI+: the intercepts of $\mathrm{R}^{2}=0.568$ and $\mathrm{Q}^{2}=-0.0 .375$, ESI-: the intercepts of $\mathrm{R}^{2}=0.518$ and $\mathrm{Q}^{2}=-0.545$. $\mathrm{Z}$ : normal group; $\mathrm{B}$ : AEE group; $\mathrm{H}: \mathrm{H}_{2} \mathrm{O}_{2}$ group.

Orthogonal projections to latent structures discriminate analysis (OPLS-DA) model was constructed and tested with the permutation test to further explore the differences in metabolites among the different treatment groups and the effect of AEE on oxidative injury. In the OPLS-DA 
analysis, the AEE group and normal group were clearly separated in the absence of $\mathrm{H}_{2} \mathrm{O}_{2}$ (Figure $4 \mathrm{c}$, d), consistent with the previous results of the PCA. Moreover, the AEE group, $\mathrm{H}_{2} \mathrm{O}_{2}$ group and normal group were clearly divided into three regions (Figure $5 \mathrm{c}, \mathrm{d}$ ). As indicated by the validation plots shown in Figures 4e,f and 5e,f, in all OPLS-DA models, permutation tests generated Q2 regression lines with a negative intercept, and all permuted $\mathrm{R} 2$ values located to the left of the intercept were lower than the original point to the right of the intercept.

After building the OPLS-DA model, a variable importance analysis was conducted as the key step before the biomarker analysis. The variables in the OPLS-DA were screened with a VIP value greater than 1.0 and $p<0.05$. Through further identification of putative metabolites, four potential biomarkers were selected and summarized in Table 2.

Table 2. The result of biomarkers identified in the cells and cell supernatants treated with AEE in the absence of $\mathrm{H}_{2} \mathrm{O}_{2}$.

\begin{tabular}{cccccccc}
\hline No. & RT & VIP & Formula & Metabolite & SM & $\mathbf{m} / \mathbf{z}$ & \multicolumn{2}{c}{ Fold Change } \\
\cline { 5 - 7 } & & & & & & AEE/C \\
\hline 1 & 3.14 & 3.39 & $\mathrm{C}_{9} \mathrm{H}_{11} \mathrm{NO}_{3}$ & L-Tyrosine & - & 181.07285 & $2.16^{*}$ \\
2 & 1.49 & 1.01 & $\mathrm{C}_{5} \mathrm{H}_{11} \mathrm{NO}_{2}$ & L-valine & + & 117.07925 & $3.17^{*}$ \\
3 & 10.56 & 2.19 & $\mathrm{C}_{7} \mathrm{H}_{12} \mathrm{O}_{5}$ & 2-Isopropylmalic acid & + & 176.06818 & 0.49 \\
4 & 5.7 & 4.093 & $\mathrm{C}_{11} \mathrm{H}_{15} \mathrm{~N}_{5} \mathrm{O}_{3} \mathrm{~S}$ & 5'-Methylthioadenosine & + & 297.08875 & 1.75 * \\
\hline
\end{tabular}

RT: retention time; VIP: variable importance in the projection; SM: scan mode; +: metabolites identified in positive mode; -: metabolites identified in negative mode. ${ }^{*} p<0.05$ compared with the normal group; AEE/C: AEE group compared with the normal group.

\subsubsection{Cellular Metabolomics Analysis}

The results from the cellular metabolomics analysis were similar to the results obtained from cell culture supernatant samples. Typical TICs of cellular extracts in positive and negative modes are shown in Supplementary materials. As shown in the PCA score plots, clear boundaries between the normal group and AEE group were observed in the absence of $\mathrm{H}_{2} \mathrm{O}_{2}$ in both positive and negative modes (Figure 4g,h). A clear separation among the normal, $\mathrm{H}_{2} \mathrm{O}_{2}$ and AEE groups was observed (Figure 5g,h). As shown in score plots of OPLS-DA models (Figures $4 \mathrm{i}, \mathrm{j}$ and $5 \mathrm{i}, \mathrm{j}$ ), clear compartmentation was also observed among the different treatment groups in the absence or presence of $\mathrm{H}_{2} \mathrm{O}_{2}$. Moreover, none of the OPLS-DA models were overfitted, according to the results of the permutation test, as shown in Figures $4 \mathrm{k}, 1$ and $5 \mathrm{k}, 1$. The Q2 regression line has a negative intercept, and all permuted R2 values located to the left of the intercept were lower than the original point to the right of the intercept.

\subsection{Identification of the Biomarkers and Pathway Analysis}

After building the OPLS-DA model, a variable importance (VIP) analysis was conducted as the key step before the biomarker analysis. The potential biomarkers were screened with a VIP value $>1$ and $p<0.05$. Then, an analysis of metabolomics pathways was performed with MetaboAnalyst 3.0 software to identify and visualize the most relevant metabolic pathways in the cells with oxidative injury. After pretreating HUVECs with different concentrations of AEE for $24 \mathrm{~h}$ in the absence of $\mathrm{H}_{2} \mathrm{O}_{2}$, four potential biomarkers were selected in the cell and cell culture supernatant samples (Table 2), which were involved in valine, leucine and isoleucine biosynthesis; aminoacyl-tRNA biosynthesis; thiamine metabolism; pantothenate and CoA biosynthesis; phenylalanine, tyrosine and tryptophan biosynthesis; pyruvate metabolism; propanoate metabolism; ubiquinone and other terpenoid-quinone biosynthesis; nitrogen metabolism; valine, leucine and isoleucine degradation; phenylalanine metabolism; cysteine and methione metabolism; and tyrosine metabolism (Figure 6A). In the $\mathrm{H}_{2} \mathrm{O}_{2}$-induced cell and cell culture supernatant samples, seven potential biomarkers were selected according to the aforementioned threshold (Table 3) and were involved in cysteine and methionine metabolism, riboflavin metabolism, biotin metabolism, lysine degradation, lysine biosynthesis, N-glycan biosynthesis, glutathione 
metabolism, aminoacyl-tRNA biosynthesis and tryptophan metabolism (Figure 6B). These results showed that there were few differential metabolites in different treatment groups, but they were involved in many metabolic pathways, which were attributed to the fact that one metabolite might hit many metabolic pathways and only one metabolite in many metabolic pathways. Therefore, many relevant metabolic pathways were only speculative, while many of these differential metabolites, such as, glutathione, riboflavin and L-valine, were relevant to endothelial repair, proliferation and anti-oxidation.
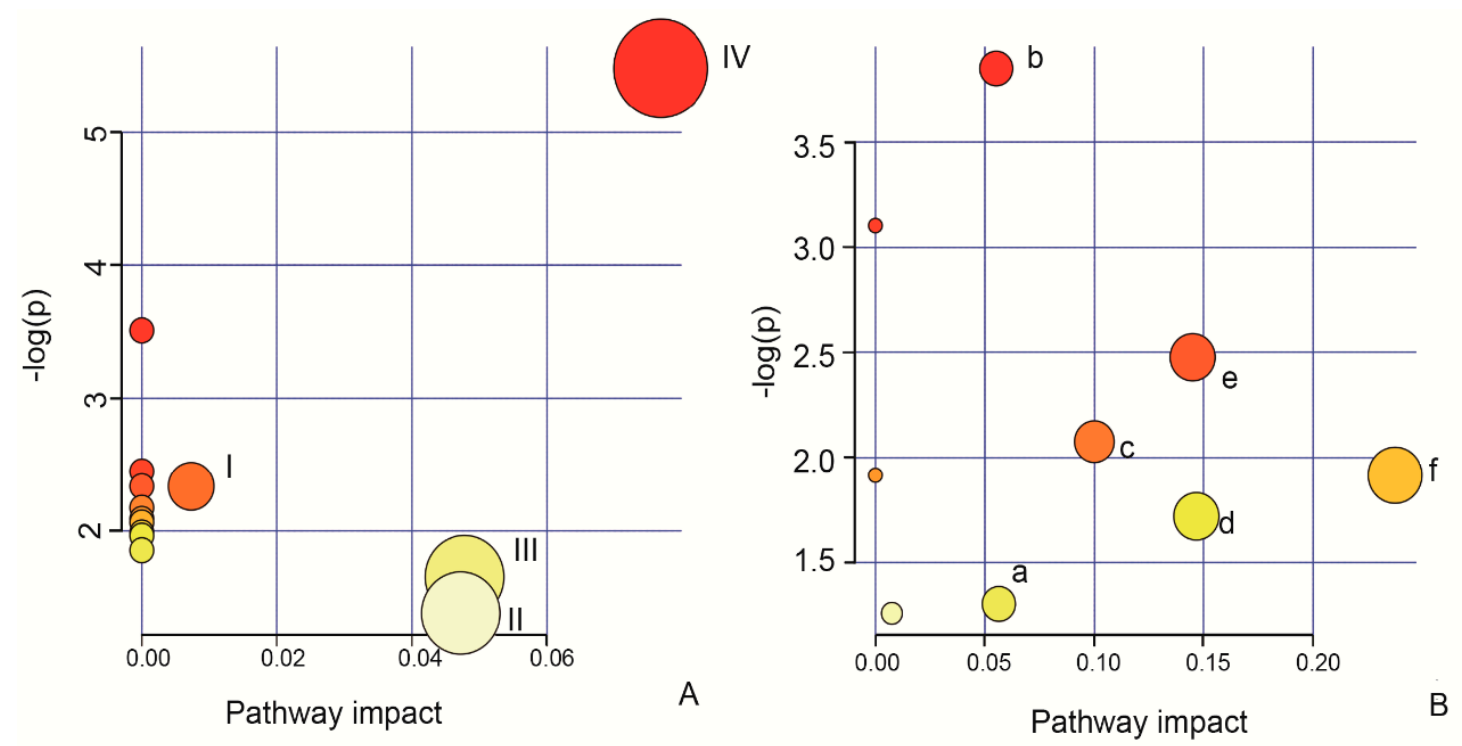

Figure 6. Results of the pathway analysis of the potential biomarkers in cells and cell culture supernatants. (A) Effect of AEE on possible metabolic pathways in the absence of $\mathrm{H}_{2} \mathrm{O}_{2}$. I: Phenylalanine, tyrosine and tryptophan biosynthesis; II: tyrosine metabolism; III: cysteine and methionine metabolism; and IV: valine, leucine and isoleucine biosynthesis. (B) Effect of AEE on possible metabolic pathways disturbed by $\mathrm{H}_{2} \mathrm{O}_{2}$. a: Aminoacyl-tRNA biosynthesis; b: cysteine and methionine metabolism; c: lysine biosynthesis; d: lysine degradation; e: riboflavin metabolism; and f: glutathione metabolism.

Table 3. The effect of AEE on the levels of potential biomarkers in cell and cell supernatants stimulated with $\mathrm{H}_{2} \mathrm{O}_{2}$.

\begin{tabular}{|c|c|c|c|c|c|c|c|c|}
\hline \multirow{2}{*}{ No. } & \multirow{2}{*}{ RT } & \multirow{2}{*}{ VIP } & \multirow{2}{*}{ Formula } & \multirow{2}{*}{ Metabolite } & \multirow{2}{*}{ SM } & \multirow{2}{*}{$\mathbf{m} / \mathbf{z}$} & \multicolumn{2}{|c|}{ Fold Change } \\
\hline & & & & & & & $\mathrm{C} / \mathrm{H}_{2} \mathrm{O}_{2}$ & $\mathrm{AEE} / \mathrm{H}_{2} \mathrm{O}_{2}$ \\
\hline 1 & 1.46 & 1.45 & $\mathrm{C}_{10} \mathrm{H}_{17} \mathrm{~N}_{3} \mathrm{O}_{6} \mathrm{~S}$ & Glutathione & +- & 307.08353 & $2.78 *$ & $1.40 *$ \\
\hline 2 & 1.14 & 1.27 & $\mathrm{C}_{6} \mathrm{H}_{14} \mathrm{~N}_{2} \mathrm{O}_{2}$ & L-Lysine & + & 146.10437 & $6.17^{*}$ & $5.16^{*}$ \\
\hline 3 & 2.04 & 4.13 & $\mathrm{C}_{11} \mathrm{H}_{16} \mathrm{~N}_{2} \mathrm{O}_{8}$ & $N$-Acetylaspartylglutamic acid & + & 304.08963 & $4.66^{*}$ & $2.85 *$ \\
\hline 4 & 5.7 & 1.96 & $\mathrm{C}_{11} \mathrm{H}_{15} \mathrm{~N}_{5} \mathrm{O}_{3} \mathrm{~S}$ & 5'-Methylthioadenosine & + & 297.08932 & $1.974 *$ & $3.32 *$ \\
\hline 5 & 16.9 & 1.94 & $\mathrm{C}_{21} \mathrm{H}_{39} \mathrm{O}_{9} \mathrm{P}$ & Dolichyl b-D-glucosyl phosphate & + & 466.2366 & $2.264 *$ & 1.028 \\
\hline 6 & 8.37 & 2.04 & $\mathrm{C}_{17} \mathrm{H}_{20} \mathrm{~N}_{4} \mathrm{O}_{6}$ & Riboflavin & + & 376.13806 & $5.77^{*}$ & $1.91 *$ \\
\hline 7 & 10.51 & 3.59 & $\mathrm{C}_{11} \mathrm{H}_{20} \mathrm{O}_{6}$ & Prenyl glucoside & + & 248.12555 & $2.69 *$ & 1.04 \\
\hline 8 & 5.21 & 2.29 & $\mathrm{C}_{10} \mathrm{H}_{9} \mathrm{NO}$ & Indole acetaldehyde & + & 159.06776 & $0.17^{*}$ & $0.69 *$ \\
\hline
\end{tabular}

RT: retention time; VIP: variable importance in the projection; SM: scan mode; +: metabolites identified in positive mode; -: metabolites identified in negative mode. Metabolites identified in both positive and negative modes; * $p<0.05$ compared with the $\mathrm{H}_{2} \mathrm{O}_{2}$ group; $\mathrm{C} / \mathrm{H}_{2} \mathrm{O}_{2}$ : normal group compared with the $\mathrm{H}_{2} \mathrm{O}_{2}$ group; $\mathrm{AEE} / \mathrm{H}_{2} \mathrm{O}_{2}$ : $\mathrm{AEE}$ group compared with the $\mathrm{H}_{2} \mathrm{O}_{2}$ group.

\section{Discussion}

The vascular endothelium, a biological semipermeable membrane between the blood and underlying tissues, has been regarded as an active endocrine, paracrine, and autocrine organ $[1,2]$. It affects vascular hemostasis by regulating platelet function, the coagulation system, and fibrinolysis [26-29]. Many cardiovascular diseases are closely related to the dysfunction of the vascular endothelium [30-32]. In the present study, the $\mathrm{H}_{2} \mathrm{O}_{2}$-induced oxidative stress model and HFD-induced 
atherosclerosis model were used to explore the effect of AEE on vascular endothelial cell dysfunction. HFD-fed rats and $\mathrm{H}_{2} \mathrm{O}_{2}$-induced vascular endothelial cells are rapid, invaluable and sensitive models of evoked vascular endothelial dysregulation in vivo and in vitro, respectively [33-36]. In vitro, after exposure to $200 \mu \mathrm{M} \mathrm{H}_{2} \mathrm{O}_{2}$ for $22 \mathrm{~h}$, the percentage of early apoptotic HUVECs and E-selectin expression in HUVECs were significantly increased. Notably, the changes in the $\mathrm{H}_{2} \mathrm{O}_{2}$-induced oxidative stress model were significantly ameliorated by the AEE treatment.

AEE is synthesized by combining aspirin with eugenol based on the prodrug principal [11]. AEE exhibits significantly reduced side effects and stronger pharmacological anti-thrombotic, anti-atherosclerotic, and anti-oxidant activities than aspirin and eugenol [12,13,37]. In the present study, AEE significantly decreased the expression of VCAM-1 and E-selectin, and decreased the adherence of THP- 1 cells to $\mathrm{H}_{2} \mathrm{O}_{2}$-induced HUVECs. Vascular cell adhesion molecule, a biomarker of endothelial dysfunction, appears to be an important mediator of the development of atherosclerosis. The overexpression of adhesion molecules in the endothelium mediates the adhesion of monocytes, lymphocytes, eosinophils, and basophils to the surface of the vascular endothelium, causing atherosclerosis [38-40]. AEE decreased VCAM-1 and E-selectin expression, which might be responsible for the anti-atherosclerotic effects. Cellular metabolomics was performed in the present study to further explore the mechanism by which AEE reduced the expression of VCAM- 1 and E-selectin. Many putative mechanisms for endothelial adhesion molecule dysfunction have been well reviewed [41]. Multiple metabolic pathways were involved in vascular endothelial dysfunction. These findings will contribute to further improving our understanding of the underlying mechanism regulating adhesion molecule levels by exploring the effects of AEE on the metabolic pathways in vascular endothelial cells.

Cellular metabolomics is an invaluable and sensitive approach for detecting alterations in metabolic pathways in response to various stimuli by investigating the levels of endogenous small molecule metabolites [19]. In the present study, the results of cell and cell culture supernatant metabolomics analyses identified four potential biomarkers in the cell and cell culture supernatant samples from HUVECs pretreated with AEE in the absence of $\mathrm{H}_{2} \mathrm{O}_{2}$ compared with the control group. These biomarkers are involved in amino acid metabolism, carbohydrate metabolism, energy metabolism, and metabolism of cofactors and vitamins. The levels of 5'-methylthioadenosine, an intermediate metabolite of L-methionine, were significantly increased in the AEE treatment groups. 5'-Methylthioadenosine is a potent A1 receptor agonist that participates in inhibiting the apoptosis of vascular endothelial cells by activating the A1 receptor [42]. After pretreating HUVECs with AEE in the absence of $\mathrm{H}_{2} \mathrm{O}_{2}$, the levels of L-tyrosine and L-valine were also markedly increased. L-Valine exerts many beneficial effects, including repairing tissues and increasing energy $[43,44]$. Researchers have speculated that AEE might enhance the endothelial repair capacity by modulating methionine and valine metabolism. After treating HUVECs with $\mathrm{H}_{2} \mathrm{O}_{2}$, the results of biomarker and pathway analyses identified eight biomarkers in the cell and cell culture supernatant samples. These biomarkers are involved in riboflavin metabolism, $\mathrm{N}$-glycan biosynthesis, and glutathione metabolism. Several of these biomarkers play pivotal roles in the pathways regulating vascular homeostasis. $\mathrm{N}$-Acetylaspartylglutamic acid, glutathione, L-lysine, and riboflavin effectively protect the vascular endothelium by inhibiting the adhesion of leukocytes to endothelial cells, maintaining the blood lipid balance, reducing oxidative stress, and enhancing anti-oxidant and vascular repair capabilities [45-50]. Indole acetaldehyde, a tryptophan metabolite, inhibits endothelial cell proliferation [51]. Notably, after the AEE treatment, the changes in the $\mathrm{H}_{2} \mathrm{O}_{2}$-induced HUVECs showed a reversible trend to a physiological level. These results of cellular metabolomics as analyses and our previous findings from plasma and urine metabonomics in HFD-fed hamsters [17] suggested that the mechanism underlying the anti-atherosclerotic effects of AEE might be related to a decrease in vascular endothelial dysfunction by ameliorating metabolic changes, increasing the anti-oxidative stress activity and decreasing adhesion molecule expression. The HFD-induced atherosclerosis model was utilized in vivo to further confirm the cytoprotective effects of AEE. 
After treating rats with HFD for 12 weeks, VCAM-1 and E-selectin expression in the aorta and the levels of sVCAM-1 and sE-selectin were increased significantly. Additionally, the levels of LDL, HDL, $\mathrm{TCH}$, and AGE significantly deviated from physiological levels, and the trends in LDL, HDL, and TCH levels were consistent with previous studies [15,37]. These findings confirmed that endothelium in HFD-fed rats had been disturbed. Excessive LDL, particularly oxidized low-density lipoproteins (ox-LDL), causes early atherosclerosis by disturbing the function of the endothelium [52-54]. Moreover, the formation of AGEs induced by various stimuli accelerates the development of atherosclerosis by increasing the expression of adhesion molecules [55-57]. In the present study, AEE reduced the increase in the serum LDL, AGE, sVCAM-1 and sE-selectin levels in HFD-fed rats and decreased VCAM-1 and E-selectin expression, which might be related to an amelioration of the excessive accumulation of LDL and AGEs in the blood vessel. Based on the results from the in-vivo and in-vitro experiments, the anti-atherosclerotic mechanism of AEE might be related to a decrease in vascular endothelial dysfunction through the amelioration of metabolic changes, an increase in the anti-oxidative stress activity, and a decrease in adhesion molecule expression. Our previous study had also confirmed that AEE could significantly enhance the anti-oxidative stress ability of vascular endothelial. It was well known that oxidative stress could stimulus the adhesion molecule expression on the vascular endothelial cells. Therefore, we proposed that the inhibiting effect of AEE on adhesion molecules was related to reduce the oxidative stress of vascular endothelium

Due to the limitations of the UPLC/QTOF-MS method for metabolomics analyses, many differentially altered metabolites are unable to be identified and thus some important biological information is missed. In the present study, the findings of the metabolomics analysis based on UPLC/QTOF-MS only partially explained the biological changes among the different treatment groups. Certainly, further studies of how AEE mutually affects these metabolic pathways are needed.

\section{Materials and Methods}

\subsection{Chemicals}

Transparent AEE crystals with a purity of $99.5 \%$ according to RE-HPLC were prepared in the Lanzhou Institute of Husbandry and Pharmaceutical Sciences of CAAS. The $\mathrm{H}_{2} \mathrm{O}_{2}$ solution (cat number: 323381), dimethyl sulfoxide (DMSO) and Trypsin-EDTA were supplied by Sigma (St. Louis, MO, USA). Deionized water (18.25 M 2 ) was prepared with a Direct-Q ${ }^{\circledR} 3$ system (Millipore, Bedford, MA, USA). The Annexin V/PE apoptosis detection kit was purchased from BD Biosciences (San Jose, CA, USA). Anti-ICAM-1, anti-VCAM-1, and anti-E-selectin antibodies were obtained from Abcam (Cambridge, MA, USA). The rat-soluble vascular cell adhesion molecule 1(sVCAM-1) ELISA kit, rat soluble intercellular adhesion molecule 1 (sICAM-1) ELISA kit, and rat soluble E-selectin (sE-selectin) ELISA kit were obtained from Elabscience (Wuhan, China); the advanced glycation end product (AGE) ELISA kit was purchased from Wuhan USCN Business Co., Ltd. (Wuhan, China). MS-grade acetonitrile was purchased from Thermo Fisher Scientific (Waltham, MA, USA). Carboxymethylcellulose sodium (CMC-Na) was supplied by Tianjin Chemical Reagent Company (Tianjin, China)

\subsection{Cell Culture and Treatments}

Human umbilical vein endothelial cells (ATCC ${ }^{\circledR}$ CRL-4053 ${ }^{\mathrm{TM}}$ ) purchased from ATCC (Rockville, MD, USA) were cultured in cell culture flasks with DMEM/F12 (1:1) supplemented with $10 \%$ fetal bovine serum. The media were refreshed once every two days. Subcultures were performed with trypsin-EDTA. Experiments were subsequently conducted on cells at passages 6-7.

HUVEC s were randomly divided into three groups: a normal group, model group and AEE pretreatment group. Cells in the normal group were incubated with the culture medium. The model group was incubated with the culture medium containing $200 \mu \mathrm{M} \mathrm{H}_{2} \mathrm{O}_{2}$ for $22 \mathrm{~h}$. In the AEE pretreatment groups, cells were pre-incubated with culture medium containing different concentrations of $\operatorname{AEE}(0.5,1$, or $2 \mu \mathrm{M})$ for $24 \mathrm{~h}$ and then incubated with medium containing $200 \mu \mathrm{M} \mathrm{H}_{2} \mathrm{O}_{2}$ for $22 \mathrm{~h}$. 


\subsection{Apoptosis Detection Using Flow Cytometry}

The apoptosis of HUVECs in the different treatment groups was quantified with an Annexin V/PE apoptosis detection kit using flow cytometry. Briefly, the cells were collected and washed three times with cold PBS. Next, cells were incubated with PE-Annexin V and stained with 7-ADD for $20 \mathrm{~min}$ at room temperature in the dark. The double-stained cells were analyzed using flow cytometry, and the following controls were used to establish compensation and quadrants: unstained cells, cells stained with PE-Annexin V and cells stained with 7-ADD.

\subsection{Adhesion Assay}

HUVECs were cultured in 96-well flat-bottom plates $(0.1 \mathrm{~mL} /$ well $)$ at a density of $1 \times 105$ cells $/ \mathrm{mL}$ for $24 \mathrm{~h}$. Cells were then pretreated with the different concentrations of AEE $(0.5,1$, or $2 \mu \mathrm{M})$ for $24 \mathrm{~h}$, followed by $200 \mu \mathrm{M} \mathrm{H}_{2} \mathrm{O}_{2}$ for $22 \mathrm{~h}$. The culture medium was then removed, and the THP- 1 cells prelabeled with BECF-AM were cocultured with the treated HUVECs at $37^{\circ} \mathrm{C}$ for $1 \mathrm{~h}$ in a $5 \% \mathrm{CO}_{2}$ incubator. The non-adherent cells were removed by gentle aspiration. Plates were washed three times with DMEM/F12 (1:1). The number of adherent cells was estimated under a microscope, and then cells were lysed with $0.1 \mathrm{~mL}$ of $0.25 \%$ Triton X-100. The fluorescence intensity was measured at an excitation wavelength of $485 \mathrm{~nm}$ and an emission wavelength of $538 \mathrm{~nm}$ using an Enspire Microplate Reader (PerkinElmer, Waltham, MA, USA).

\subsection{Adhesion Molecule Expression}

HUVECs were grown to confluence, pretreated with AEE for $24 \mathrm{~h}$ and stimulated with $200 \mu \mathrm{M} \mathrm{H}_{2} \mathrm{O}_{2}$ for $22 \mathrm{~h}$ to determine whether AEE modified the $\mathrm{H}_{2} \mathrm{O}_{2}$-induced expression of adhesion molecules. At the end of the stimulation period, HUVECs were harvested, incubated with anti-VCAM-1, anti-ICAM-1, and anti-E-selectin antibodies for $1 \mathrm{~h}$ at room temperature, and then incubated with an Alexa Fluor 488-labeled secondary antibody. After HUVECs were washed three times, their immunofluorescence intensity was analyzed using flow cytometry.

\subsection{Cellular Metabolite Extraction}

After incubation, the cell culture supernatant was collected, centrifuged at $800 \mathrm{rpm}$ for $10 \mathrm{~min}$ at $4{ }^{\circ} \mathrm{C}$ and the supernatant was transferred into clean tubes. Twenty microliters of supernatant from each sample were mixed to prepare a quality control (QC) sample. Then, the mixture was divided into aliquots with the same volume as other samples and prepared using the method described below. Methanol was added to the supernatant $(3: 1, v / v)$, vortexed for $1 \mathrm{~min}$, incubated at $4{ }^{\circ} \mathrm{C}$ for $30 \mathrm{~min}$, and centrifuged at $14000 \mathrm{~g}$ for $10 \mathrm{~min}$ at $4{ }^{\circ} \mathrm{C}$. The supernatant was transferred to a new tube and dried with a stream of nitrogen. The residue was resuspended in $500 \mu \mathrm{L}$ of methanol/water $(3: 1, v / v)$ and then filtered through a $0.2-\mu \mathrm{m}$ nylon mesh into sample vials.

After collecting the supernatant from cultured cells, the cells were quickly quenched by adding $80 \%$ methanol $\left(v / v\right.$, cooled to $\left.-80^{\circ} \mathrm{C}\right)$, incubating the mixture at $-80^{\circ} \mathrm{C}$ for $5 \mathrm{~min}$, and scraping the cells from the cell culture plate. Then, the mixture was lysed with two freeze-thaw cycles (frozen in liquid nitrogen and thawing at $37^{\circ} \mathrm{C}$ ), mixed for $1 \mathrm{~min}$, and pelleted by centrifugation at $14000 \times \mathrm{g}$ for $10 \mathrm{~min}$ at $4{ }^{\circ} \mathrm{C}$. Twenty microliters of supernatant from each sample were mixed to prepare a quality control (QC) sample. Then, the mixture was divided into aliquots with the same volume as other samples and prepared together. The supernatant was filtered through a $0.2-\mu \mathrm{m}$ nylon mesh into sample vials.

\subsection{UPLC/QTOF-MS Analysis of Cellular Metabolites}

The metabolomics analysis was performed with an Agilent 1290 Infinity LC system coupled to an Agilent 6530 Accurate-mass Q-TOF mass spectrometer (Agilent Technologies, Palo Alto, CA, USA). Chromatographic separation of cell and cell culture supernatant samples was performed on an Agilent ZORBAX SB-C18 threaded column $(2.1 \times 150$ mm, $1.8 \mu \mathrm{m}$, Agilent Technologies, Palo Alto, CA, USA) 
maintained at $35^{\circ} \mathrm{C}$. The mobile phase consisted of solvent $\mathrm{A}(0.1 \%$ formic acid in water, $v / v)$ and $\mathrm{B}$ $(0.1 \%$ formic acid in acetonitrile, $v / v)$. The optimized gradient program was established. The post time was set to $3 \mathrm{~min}$ for equilibration. Mass spectrometry was performed in both positive (ESI+) and negative (ESI-) electrospray ionization modes. The fragment voltage was set to $135 \mathrm{~V}$ and the skimmer voltage was set to $65 \mathrm{~V}$. The capillary voltages were set to $4.0 \mathrm{KV}$ in positive mode and $3.5 \mathrm{KV}$ in negative mode. The drying gas (nitrogen) was used at a flow rate of $10 \mathrm{~L} / \mathrm{min}$ at $350{ }^{\circ} \mathrm{C}$ and the nebulizer pressure was set to $45 \mathrm{psig}$. Data were collected in centroid mode from $50-1000 \mathrm{~m} / \mathrm{z}$ using an extended dynamic model.

The raw MS data were initially processed with the Mass Profiler Professional (MPP) software (Agilent Technologies, USA) to filter noise, correct the baseline, align peaks, and identity and quantify peaks. The match tolerance of mass span is $10 \mathrm{ppm}$, and the match tolerance of retention time's span is $0.10 \mathrm{~min}$. The obtained data were imported into SIMCA-P (version 13.0, Umetrics AB, Umea, Sweden), where a principal component analysis (PCA) and partial least squares discriminant analysis (OPLS-DA) were performed on the dataset. The quality of OPLS-DA models was described by R2X, R2Y, and Q2, and its validity was evaluated by performing permutation testing (with 200 permutations). The variable importance in the projection (VIP $>1$ ) value of the validated OPLS-DA model and the $p$ values from one-way ANOVA $(p<0.05)$ were used as the measurement indices to select potential metabolites. Metabolites were identified through a mass-based search followed by manual verification. Accurate mass values of the molecular ions of interest in TOF-MS data were searched against METLIN and Human Metabolome Database (HMDB). Then, an MS/MS analysis was conducted to confirm the structure of potential biomarkers by matching the masses of the fragments. The parent ion mass tolerance is $\pm 10 \mathrm{ppm}$ and mass/charge $(\mathrm{m} / \mathrm{z})$ of products tolerance is $\pm 10 \mathrm{ppm}$. The clustering analysis of the potential biomarkers and pathway analysis were performed using MetaboAnalyst 3.0 [58] and the metabolic pathways were identified using the KEGG database.

\subsection{Animal Experiment}

Thirty male Sprague-Dawley (SD) rats (6 weeks old) weighing 120-130 g were purchased from the Laboratory Animal Center of Lanzhou Veterinary Research Institute (Lanzhou, China). All animals were housed in groups in the facilities at a controlled relative humidity (45-65\%) and temperature $\left(22 \pm 2{ }^{\circ} \mathrm{C}\right)$. Feed and drinking water were supplied to the SD rats ad libitum. The rats were randomly assigned into three groups $(n=10)$ : (1) the control group, in which rats were fed the normal diet; (2) the high-fat diet (HFD) group, in which rats were fed the HFD; and (3) the AEE group, in which rats were simultaneously fed the HFD and AEE ( $54 \mathrm{mg} / \mathrm{kg}$ body weight). The normal diet (12.3\% lipids, $63.3 \%$ carbohydrates and $24.4 \%$ proteins) was purchased from Keao Xieli Feed Co., Ltd. (Beijing, China) and the HFD (41.5\% lipids, $40.2 \%$ carbohydrates and $18.3 \%$ proteins) was customized from Keao Xieli Feed Co., Ltd. The dose of AEE was selected according to previous studies from our group $[37,59]$. Rats were sacrificed by injecting pentobarbital ( $30 \mathrm{mg} / \mathrm{kg}$ body weight). Blood samples were collected from the heart into heparin-treated vacuum tubes. Plasma samples were obtained after the centrifugation of blood at $3500 \mathrm{rpm}$ for $10 \mathrm{~min}$ at $4{ }^{\circ} \mathrm{C}$ and stored at $-80^{\circ} \mathrm{C}$ until analysis. The aortas were carefully isolated from rats and fixed with $4 \%$ formalin for pathological observations. All experimental protocols and procedures were approved by the Institutional Animal Care and Use Committee of Lanzhou Institute of Husbandry and Pharmaceutical Science of Chinese Academy of Agricultural Sciences (Approval No. NKMYD201805; Approval Date: 18 October 2018). Animal welfare and experimental procedures were performed strictly in accordance with the Guidelines for the Care and Use of Laboratory Animals issued by the US National Institutes of Health.

\subsection{Measurement of Serum AGE Levels}

Serum AGE levels were detected using an enzyme-linked immunosorbent assay kit for AGEs according to the manufacturer's protocols. 


\subsection{Adhesion Molecule Expression in the Aorta}

Aortas were formalin-fixed, quick-frozen in liquid nitrogen, sectioned, and antigens were retrieved to investigate the expression of VCAM-1, ICAM-1, and E-selectin in the aorta. Sections were incubated with primary antibodies against VCAM-1, ICAM-1, and E-selectin. Then, sections were incubated with an Alexa Fluor 488-labeled goat anti-rabbit antibody using the standard protocol. Moreover, the aortas that were only incubated with the Alexa Fluor 488-labeled goat anti-rabbit antibody served as the negative control. The result was observed and analyzed with a laser scanning confocal microscope and Zen blue version 2.3 software (ZEISS LSM-800, Jena, Germany).

\subsection{Serum Levels of Adhesion Molecules}

Serum levels of sVCAM-1, sICAM-1 and sE-selectin were detected with the indicated ELISA kits according to the manufacturer's protocols.

\subsection{Statistical Analysis}

Statistical analyses were performed using SAS 9.2 software (SAS Institute Inc., Cary, NC, USA). All data are presented as the means \pm SD. The differences among groups were analyzed with one-way analysis of variance (ANOVA). When significance was achieved, Duncan's multiple comparisons test was conducted to identify the sources of differences. Statistical significance was considered at $p<0.05$.

\section{Conclusions}

AEE effectively protected the vascular endothelium by enhancing anti-oxidant and vascular repair capabilities and inhibiting the adhesion of leukocytes to endothelial cells. The inhibiting effect of AEE on adhesion molecules was related to reduced oxidative stress of vascular endothelial by ameliorating the vascular endothelium metabolism.

Supplementary Materials: Supplementary materials can be found at http://www.mdpi.com/1422-0067/20/13/ 3165/s1.

Author Contributions: J.-Y.L. and M.-Z.H. designed and performed the experiments and wrote the manuscript. X.-R.L. and Y.-J.Y. synthesized and purified AEE. X.-W.L. and Z.Q. assisted with the animal experiments. J.-Y.L. supervised the study and revised the manuscript.

Funding: This study was supported by grants from the National Natural Science Foundation of China (grant number. 31572573 and 31872518).

Acknowledgments: Thanks to N. Ma and L. Liu for their technical support.

Conflicts of Interest: The authors declare no conflict of interest.

\section{Abbreviations}

$\begin{array}{ll}\text { HUVECs } & \text { Human umbilical vein endothelial cells } \\ \text { HFD } & \text { High fat diet } \\ \text { VCAM-1 } & \text { Vascular cell adhesion molecule 1 } \\ \text { ICAM-1 } & \text { Soluble intercellular adhesion molecule 1 } \\ \text { MDA } & \text { Malondialdehyde } \\ \text { HDL } & \text { High density lipoprotein } \\ \text { AGEs } & \text { Advanced glycosylation end products } \\ \text { LDL } & \text { Low density lipoprotein } \\ \text { TCH } & \text { Total cholesterol } \\ \text { PCA } & \text { Principal component analysis } \\ \text { OPLS-DA } & \text { Orthogonal projections to latent structures discriminate analysis } \\ \text { VIP } & \text { Variable importance in the projection } \\ \text { UPLC/QTOF-MS } & \text { Ultra-performance liquid chromatography/quadrupole time of flight-mass spectrometry }\end{array}$




\section{References}

1. Henderson, J.; Henderson, I.W. The endocrine function of the vascular endothelium. J. Biol. Educ. 1995, 29, 104-109. [CrossRef]

2. Hurairah, H.; Ferro, A. The role of the endothelium in the control of vascular function. Int. J. Clin. Pract. 2004, 58, 173-183. [CrossRef]

3. Henrion, D. Endoplasmic reticulum stress and vascular endothelium dysfunction. Fundam. Clin. Pharmacol. 2013, 27, 4 .

4. Jamwal, S.; Sharma, S. Vascular endothelium dysfunction: A conservative target in metabolic disorders. Inflamm. Res. 2018, 67, 391-405. [CrossRef] [PubMed]

5. Markov, C.M. Molecular mechanisms of dysfunction of vascular endothelium. Kardiologiya 2005, 45, 62-72.

6. Vestweber, D. How leukocytes cross the vascular endothelium. Nat. Rev. Immunol. 2015, 15, 692-704. [CrossRef]

7. Cai, J.J.; Wen, J.; Jiang, W.H.; Lin, J.; Hong, Y.; Zhu, Y.S. Androgen actions on endothelium functions and cardiovascular diseases. J. Geriatr. Cardiol. 2016, 13, 183-196.

8. Lin, P.J.; Chang, C.H. Endothelium dysfunction in cardiovascular diseases. Chang Yi Xue Za Zhi 1994, 17, 198-210.

9. Nair, A.R.; Agbor, L.N.; Mukohda, M.; Hu, C.Y.; Wu, J.; Sigmund, C.D. Interference with ppar gamma in the endothelium causes cerebral vascular dysfunction in response to endogenous renin-angiotensin system activation. FASEB J. 2017, 31.

10. Onyangunga, O.; Moodley, J.; Odun-Ayo, F.; Naicker, T. The impact of antiretroviral drugs in placental vascular endothelium dysfunction. Placenta 2017, 57, 273-274. [CrossRef]

11. Li, J.Y.; Yu, Y.G.; Wang, Q.W.; Zhang, J.Y.; Yang, Y.J.; Li, B.; Zhou, X.Z.; Niu, J.R.; Wei, X.J.; Liu, X.W.; et al. Synthesis of aspirin eugenol ester and its biological activity. Med. Chem. Res. 2012, 21, 995-999. [CrossRef]

12. Ma, N.; Liu, X.W.; Yang, Y.J.; Li, J.Y.; Mohamed, I.; Liu, G.R.; Zhang, J.Y. Preventive effect of aspirin eugenol ester on thrombosis in kappa-carrageenan-induced rat tail thrombosis model. PLoS ONE 2015, 10, e0133125.

13. Ma, N.; Liu, X.W.; Yang, Y.J.; Shen, D.S.; Zhao, X.L.; Mohamed, I.; Kong, X.J.; Li, J.Y. Evaluation on antithrombotic effect of aspirin eugenol ester from the view of platelet aggregation, hemorheology, txb2/6-keto-pgf1alpha and blood biochemistry in rat model. BMC Vet. Res. 2016, 12, 108. [CrossRef] [PubMed]

14. Ma, N.; Yang, G.Z.; Liu, X.W.; Yang, Y.J.; Mohamed, I.; Liu, G.R.; Li, J.Y. Impact of aspirin eugenol ester on cyclooxygenase-1, cyclooxygenase-2, c-reactive protein, prothrombin and arachidonate 5-lipoxygenase in healthy rats. Iran. J. Pharm. Res. 2017, 16, 1443-1451. [PubMed]

15. Ma, N.; Yang, Y.; Liu, X.; Kong, X.; Li, S.; Qin, Z.; Jiao, Z.; Li, J. Uplc-q-tof/ms-based metabonomic studies on the intervention effects of aspirin eugenol ester in atherosclerosis hamsters. Sci. Rep. 2017, 7. [CrossRef]

16. Li, J.; Yu, Y.; Yang, Y.; Liu, X.; Zhang, J.; Li, B.; Zhou, X.; Niu, J.; Wei, X. Antioxidant activity of aspirin eugenol ester for aging model of mice by d-galactose. J. Anim. Vet. Adv. 2012, 11, 4401-4405.

17. Ma, N.; Karam, I.; Liu, X.W.; Kong, X.J.; Qin, Z.; Li, S.H.; Jiao, Z.H.; Dong, P.C.; Yang, Y.J.; Li, J.Y. Uplc-q-tof/ms-based urine and plasma metabonomics study on the ameliorative effects of aspirin eugenol ester in hyperlipidemia rats. Toxicol. Appl. Pharmacol. 2017, 332, 40-51. [CrossRef]

18. Ma, N.; Liu, X.W.; Kong, X.J.; Li, S.H.; Jiao, Z.H.; Qin, Z.; Yang, Y.J.; Li, J.Y. Aspirin eugenol ester regulates cecal contents metabolomic profile and microbiota in an animal model of hyperlipidemia. BMC Vet. Res. 2018, 14, 405. [CrossRef]

19. Baharum, S.N.; Azizan, K.A. Metabolomics in systems biology. Adv. Exp. Med. Biol. 2018, 1102, 51-68.

20. Balashova, E.E.; Maslov, D.L.; Lokhov, P.G. A metabolomics approach to pharmacotherapy personalization. J. Pers. Med. 2018, 8. [CrossRef]

21. Kargul, J.; Irminger-Finger, I.; Laurent, G.J. Metabolomics: Taking snapshots of cellular physiology in health and disease. Int. J. Biochem. Cell Biol. 2017, 93, 86. [CrossRef] [PubMed]

22. Lains, I.; Gantner, M.; Murinello, S.; Lasky-Su, J.A.; Miller, J.W.; Friedlander, M.; Husain, D. Metabolomics in the study of retinal health and disease. Prog. Retin. Eye Res. 2019, 69, 57-79. [CrossRef] [PubMed]

23. Olesti, E.; De Toma, I.; Ramaekers, J.G.; Brunt, T.M.; Carbo, M.L.; Fernandez-Aviles, C.; Robledo, P.; Farre, M.; Dierssen, M.; Pozo, O.J.; et al. Metabolomics predicts the pharmacological profile of new psychoactive substances. J. Psychopharmacol. 2019, 33, 347-354. [CrossRef] [PubMed] 
24. Wang, N.; Wei, J.; Liu, Y.; Pei, D.; Hu, Q.; Wang, Y.; Di, D. Discovery of biomarkers for oxidative stress based on cellular metabolomics. Biomarkers 2016, 21, 449-457. [CrossRef] [PubMed]

25. Saito, N.; Ohashi, Y.; Soga, T.; Tomita, M. Unveiling cellular biochemical reactions via metabolomics-driven approaches. Curr. Opin. Microbiol. 2010, 13, 358-362. [CrossRef] [PubMed]

26. Silveri, F.; De Angelis, R.; Argentati, F.; Brecciaroli, D.; Muti, S.; Cervini, C. Hypertrophic osteoarthropathy: Endothelium and platelet function. Clin. Rheumatol. 1996, 15, 435-439. [CrossRef] [PubMed]

27. Stern, D.M.; Kaiser, E.; Nawroth, P.P. Regulation of the coagulation system by vascular endothelial cells. Haemostasis 1988, 18, 202-214. [CrossRef] [PubMed]

28. Butta, N.V.; Fernandez-Bello, I.; Lopez-Longo, F.J.; Jimenez-Yuste, V. Endothelial dysfunction and altered coagulation as mediators of thromboembolism in behcet disease. Semin. Thromb. Hemost. 2015, 41, 621-628. [PubMed]

29. Ivanciu, L.; Stalker, T.J. Spatiotemporal regulation of coagulation and platelet activation during the hemostatic response in vivo. J. Thromb. Haemost. 2015, 13, 1949-1959. [CrossRef]

30. Mensah, G.A.; Ryan, U.S.; Hooper, W.C.; Engelgau, M.M.; Callow, A.D.; Kapuku, G.K.; Mantovani, A. Vascular endothelium summary statement ii: Cardiovascular disease prevention and control. Vasc. Pharm. 2007, 46, 318-320. [CrossRef]

31. Ramli, J.; CalderonArtero, P.; Block, R.C.; Mousa, S.A. Novel therapeutic targets for preserving a healthy endothelium: Strategies for reducing the risk of vascular and cardiovascular disease. Cardiol. J. 2011, 18, 352-363. [PubMed]

32. Heitzer, T.; Schlinzig, T.; Krohn, K.; Meinertz, T.; Munzel, T. Endothelial dysfunction, oxidative stress, and risk of cardiovascular events in patients with coronary artery disease. Circulation 2001, 104, 2673-2678. [CrossRef] [PubMed]

33. Hurst, J.; Kuehn, S.; Jashari, A.; Tsai, T.; Bartz-Schmidt, K.U.; Schnichels, S.; Joachim, S.C. A novel porcine ex vivo retina culture model for oxidative stress induced by $\mathrm{h}(2) \mathrm{o}(2)$. Altern. Lab. Anim. 2017, 45, 11-25. [CrossRef] [PubMed]

34. Kaczara, P.; Sarna, T.; Burke, J.M. Dynamics of h2o2 availability to arpe-19 cultures in models of oxidative stress. Free Radic. Biol. Med. 2010, 48, 1064-1070. [CrossRef] [PubMed]

35. Fang, J.; Tang, M. Exercise improves high fat diet-impaired vascular function. Biomed. Rep. 2017, 7, 337-342. [CrossRef] [PubMed]

36. Kaprinay, B.; Liptak, B.; Slovak, L.; Svik, K.; Knezl, V.; Sotnikova, R.; Gasparova, Z. Hypertriglyceridemic rats fed high fat diet as a model of metabolic syndrome. Physiol. Res. 2016, 65, S515-S518.

37. Karam, I.; Ma, N.; Liu, X.W.; Li, S.H.; Kong, X.J.; Li, J.Y.; Yang, Y.J. Regulation effect of aspirin eugenol ester on blood lipids in wistar rats with hyperlipidemia. BMC Vet. Res. 2015, 11. [CrossRef]

38. Segeda, I.; Shevchuk, S.; Kuvikova, I. Soluble vascular cell adhesion molecule-1 level in patients with anthiphospolipid syndrome: Its association with disease activity and endothelium dysfunction. Rheumatology 2012, 51, 181.

39. Chen, N.G.; Han, X. Dual function of troglitazone in icam-1 gene expression in human vascular endothelium. Biochem. Biophys. Res. Commun. 2001, 282, 717-722. [CrossRef]

40. Hallahan, D.; Kuchibhotla, J.; Wyble, C. Cell adhesion molecules mediate radiation-induced leukocyte adhesion to the vascular endothelium. Cancer Res. 1996, 56, 5150-5155.

41. Chi, Z.; Melendez, A.J. Role of cell adhesion molecules and immune-cell migration in the initiation, onset and development of atherosclerosis. Cell Adhes. Migr. 2007, 1, 171-175. [CrossRef] [PubMed]

42. Munshi, R.; Clanachan, A.S.; Baer, H.P. 5'-deoxy-5'-methylthioadenosine: A nucleoside which differentiates between adenosine receptor types. Biochem. Pharm. 1988, 37, 2085-2089. [CrossRef]

43. Lazzaro, V.A.; Walker, R.J.; Duggin, G.G.; Phippard, A.; Horvath, J.S.; Tiller, D.J. Inhibition of fibroblast proliferation in l-valine reduced selective media. Res. Commun. Chem. Pathol. Pharmacol. 1992, 75, 39-48. [PubMed]

44. Selamnia, M.; Robert, V.; Mayeur, C.; Duee, P.H.; Blachier, F. Effects of 1-valine on growth and polyamine metabolism in human colon carcinoma cells. Biochim. Biophys Acta 1998, 1379, 151-160. [CrossRef]

45. Bouhlal, H.; Blondin, C.; Haeffner-Cavaillon, N.; Goldschmidt, P. n acetyl-aspartyl glutamic acid (naaga) inhibits the adhesion of leukocytes to activated endothelial cells and down-modulates the cytokine-induced expression of adhesion molecules. J. Fr. D'ophtalmologie 2002, 25, 993-1000. 
46. Chen, J.; Wu, F.; Long, Y.; Yu, W. Glutathione supplementation attenuates oxidative stress and improves vascular hyporesponsiveness in experimental obstructive jaundice. Oxid. Med. Cell Longev. 2015, 2015, 486148. [CrossRef] [PubMed]

47. Tang, Y.; Zhang, W.; Zhang, Y.; Wang, W.; Yao, F.; Yan, J.; Wan, C. 5'-methylthioadenosine attenuates ischemia reperfusion injury after liver transplantation in rats. Inflammation 2014, 37, 1366-1373. [CrossRef] [PubMed]

48. Simile, M.M.; Banni, S.; Angioni, E.; Carta, G.; De Miglio, M.R.; Muroni, M.R.; Calvisi, D.F.; Carru, A.; Pascale, R.M.; Feo, F. 5'-methylthioadenosine administration prevents lipid peroxidation and fibrogenesis induced in rat liver by carbon-tetrachloride intoxication. J. Hepatol. 2001, 34, 386-394. [CrossRef]

49. Ashoori, M.; Saedisomeolia, A. Riboflavin (vitamin b(2)) and oxidative stress: A review. Br. J. Nutr. 2014, 111, 1985-1991. [CrossRef] [PubMed]

50. Xu, P.; Zheng, Y.; Zhu, X.; Li, S.; Zhou, C. L-lysine and l-arginine inhibit the oxidation of lipids and proteins of emulsion sausage by chelating iron ion and scavenging radical. Asian-Australas. J. Anim. Sci. 2018, 31, 905-913. [CrossRef]

51. Dou, L.; Bertrand, E.; Cerini, C.; Faure, V.; Sampol, J.; Vanholder, R.; Berland, Y.; Brunet, P. The uremic solutes p-cresol and indoxyl sulfate inhibit endothelial proliferation and wound repair. Kidney Int. 2004, 65, 442-451. [CrossRef] [PubMed]

52. Takenaka, T.; Takahashi, K.; Kobayashi, T.; Oshima, E.; Iwasaki, S.; Suzuki, H. Oxidized low density lipoprotein (ox-ldl) as a marker of atherosclerosis in hemodialysis (hd) patients. Clin. Nephrol. 2002, 58, 33-37. [CrossRef] [PubMed]

53. Alique, M.; Luna, C.; Carracedo, J.; Ramirez, R. LDL biochemical modifications: A link between atherosclerosis and aging. Food Nutr. Res. 2015, 59. [CrossRef] [PubMed]

54. Bartels, E.D.; Christoffersen, C.; Lindholm, M.W.; Nielsen, L.B. Altered metabolism of ldl in the arterial wall precedes atherosclerosis regression. Circ. Res. 2015, 117, 933-942. [CrossRef] [PubMed]

55. Schleicher, E.; Friess, U. Oxidative stress, age, and atherosclerosis. Kidney Int. 2007, 72, S17-S26. [CrossRef] [PubMed]

56. McNair, E.; Qureshi, M.; Prasad, K.; Pearce, C. Atherosclerosis and the hypercholesterolemic age-rage axis. Int. J. Angiol. 2016, 25, 110-116.

57. Yamagishi, S.I.; Matsui, T. Role of hyperglycemia-induced advanced glycation end product (age) accumulation in atherosclerosis. Ann. Vasc. Dis. 2018, 11, 253-258. [CrossRef]

58. Xia, L.; Sinelnikov, I.V.; Han, B.; Wishart, D.S. MetaboAnalyst 3.0-Making metabolomics more meaningful. Nucleic Acids. Res. 2015, 43, W251-W257. [CrossRef]

59. Karam, I.; Ma, N.; Liu, X.W.; Kong, X.J.; Zhao, X.L.; Yang, Y.J.; Li, J.Y. Lowering effects of aspirin eugenol ester on blood lipids in rats with high fat diet. Lipids Health Dis. 2016, 15, 1-5. [CrossRef] 